\title{
Learning Style Preferences in College Students with Different Majors
}

\author{
I-Ju Chen ${ }^{1}$, Kai-Ru Cheng ${ }^{2}$ \\ ${ }^{1}$ Ling Tung University, Taiwan \\ ${ }^{2}$ Language Center, Ling Tung University
}

\begin{abstract}
In this study, we investigated the learning style preferences of college students with different majors and the relationship between learning styles and the majors. In total, 120 English as a foreign language college students with different majors from Taiwan participated. Descriptive statistical analysis and the chi-square test results indicated that learners across majors generally preferred the visual learning style. However, business and information technology majors preferred the auditory learning style and design majors preferred the haptic learning style. Nevertheless, although learning background may play a vital role in the development of a student's learning style, the differences between learning style preferences and educational background were non-significant. Learning style preferences may also relate to other variables and may change over time, across contexts, and between different tasks.
\end{abstract} *Correspondence to Author: I-Ju Chen

Ling Tung University, Taiwan

How to cite this article:

I-Ju Chen, Kai-Ru Cheng.Learning Style Preferences in College Students with Different Majors. American Journal of Educational Research and Reviews, 2021; 6:81.

Keywords: Learning styles; EFL learners; Visual style; Auditory style; Haptic style

\section{eScîPub}

eSciPub LLC, Houston, TX USA. Website: https://escipub.com/ 
Learning is a complex process involving knowledge acquisition through the transformation of experience; as such, it may be affected by factors related to the learning atmosphere and the learners (Bicer, 2014; Soureshjani \& Naseri, 2012). Learning processes vary from person to person due to biological and psychological differences. Each learner has individual attributes related to their learning process (Abidin et al., 2011). Individuals use different learning styles to adapt to different situations (Kolb, 1984, as cited in Soureshjani \& Naseri, 2012) and learning styles affect learning outcomes (Bicer, 2014). Many researchers found that students with multiple learning styles acquire greater learning outcomes (Claxon \& Murrel, 1987; Felder, 1995; Reid, 1987, as cited in Soureshjani \& Naseri, 2012). However, learning styles have been considered an insignificant factor in the learning process and thus largely ignored (Soureshjani \& Naseri, 2012).

A trend in foreign language learning settings is to raise awareness of individual differences and their effect on individual learning processes (Sadeghi, et al., 2012, as cited in Gohar \& Sadeghi, 2015). Language learning styles are considered the most crucial variable influencing acquisition of a second language (Oxford, 1989, as cited in Gohar \& Sadeghi, 2015).

An individual's learning style determines their approach used to concentrate on, process, internalize, and retain new information (Awang et al., 2017) and is a consistent means of processing information (Naserieh \& Sarab,
2013). A learning style is a biologically and developmentally imposed set of characteristics, and it makes learning more effective (Naserieh \& Sarab, 2013). Learners with different learning styles absorb information in a manner consistent with their preferred method of acquiring and processing information (Montgomery, 1995, as cited in Naserieh \& Sarab, 2013). Specifically, learning styles intertwine with cognitive, affective, and physiological traits that reflect a valid psychological construct and determine academic achievement (Keefe, 1990; Sims et al., 1989, as cited in Gohar \& Sadeghi, 2015).

Studies have shown that learning styles are context dependent. The way information is perceived, processed and stored varies across individuals and is influenced by environment and past experience. Learning styles are often characteristic of different cultures; learners from diverse cultural backgrounds exhibit different perceptual patterns of learning style preferences (Reid, 1987; Rossi-Le, 1995; Tyacke, 1998, as cited in Naserieh \& Sarab, 2013). Moreover, learning styles are developmental and this may change over time; they may also differ across cultures because the country or nationality of learners strongly affects learning style (Naserieh \& Sarab, 2013).

Many recent studies on learning styles and majors (e.g., Alkooheji \& Al-Hattami, 2018; Chen et al., 2018; Power, 2016) have indicated that style preferences appear to be vary among students of different majors. Liu et al. (2013) explored the learning style preferences of students from different academic backgrounds and reported that the major differences in the AJERR: https://escipub.com/american-journal-of-educational-research-and-reviews/ 
four learning styles were dependent, analytical, holistic, and random. Naserieh and Sarab (2013) conducted a study to examine the relationship between learning styles and background variables and found that students in technical fields were significantly more tactile than those in social sciences. Research suggests that social science and humanities majors favor an individualized learning experience while students in technical fields disfavor working alone. Jiraporncharoen et al. (2015) explored the associations between learning styles and high academic achievement in preclinical and clinical students and found a correlation between a sequential learning style and high academic achievement in both groups, whereas a reflective learning style was associated with high achievement among preclinical students. By using the Visual, Aural, Read/Write, Kinesthetic (VARK) questionnaire, SarabiAsiabar et al. (2015) conducted a study on students in Iran and examined the relationships between learning style preferences and gender, educational major, and status; they identified a significant association only between gender and single-modal learning styles $(p=.009)$ and status and learning styles $(p=.04)$. No significant relationship was found between educational majors (medicine, pharmacy, dentistry, health services management, and nursing) and learning styles $(p=.23)$. The dominant style among all participants was visual, followed by aural, reading/writing, and finally, kinesthetic. By using both the Kolb and VARK learning styles inventories (Kolb, 1984; Fleming \& Mills, 1992), Power (2016) conducted a study to examine the learning style preferences of college students and found that music students showed a strong preference for the active experimentation learning style and an aversion to the concrete experience learning style. Furthermore, the satisfaction of these music students corresponded directly to the active experimentation learning style. Chen et al. (2018) found that accounting majors favored a sequential approach and were less comfortable than non-accounting majors in taking a global approach to problem-solving. Alkooheji and AlHattami (2018) examined individual preferences of different college majors and found that information technology (IT) students preferred a visual learning style, followed by kinesthetic, auditory, and read/write. Art students' learning style preferences were, respectively, visual, kinesthetic, auditory, and read/write. Engineering and science students preferred the kinesthetic learning style, followed by visual, auditory, and read/write.

Research findings have led to proposals for different categories, theories, criteria, and aspects of learning styles (Cimermanava, 2018), which in turn has resulted in various new learning style assessment methods. These include the Learning Style Inventory (ISL) of Kolb (1984), Perceptual Learning Style Preference Questionnaire of Reid (1984), Learning Channel Preference Checklist (LCPC) of O'Brien (1990), Productivity Environmental Preference Survey of Dunn et al. (1991), VARK Learning Style of Fleming (1995), VARK Learning Styles Inventory of Fleming \& Mills (1992), Grasha-Riechmann Learning Style 
Scale of Riechmann and Grasha (1974), Building Excellence of Ruddle and Dunn (2000), Felder-Silverman Index of Learning Styles (ILS) of Felder and Silverman (1988), and ILS of Felder and Soloman (1996).

The reliability or validity of instruments for assessing learning styles appears problematic when applied across different cultures (Bailey et al., 2000; Cutolo et al., 2007). Consequently, researchers have called for more studies, citing a need for learning style studies focused on different perspectives (Gohar \& Sadeghi, 2015; Bicer, 2014; Soureshjani \& Naseri, 2012), contextualization (Uhrig, 2015), and the changes of style or learners' adaptability in different courses (Chen et al., 2018). Although studies on the relationship between learning styles and student majors have been conducted with different instruments, research on the relationship between learning styles and different majors in terms of English as a foreign language $(E F L)$ learning are limited. As the findings of Dai et al. (2015) summarized, when students from different majors are placed together in a college EFL class, teachers need to understand how motivation, English language proficiency, and learning styles are interrelated in EFL learning. Given this background, the present study aimed to facilitate the identification of learning style preferences of different college majors specific to EFL learning by exploring the patterns of learning style preferences among different majors. To fulfill this objective, the following questions were addressed: (1) What are the general tendencies of learning styles in terms of different majors? and (2) Are there any significant differences between learning styles and learners' majors?

\section{Methodology}

\section{Participants}

The participants were 120 first-year EFL college students (age, 18-20 years; 47 (39.17\%) men and $73(60.83 \%)$ women) at a university in Central Taiwan. They included 40 participants randomly drawn from three different fields with freshman English as a mandatory course. The three fields were business, IT, and design, and each field was treated as a cluster. The business, IT, and design students comprised respectively 16, 23, and 8 men and 24, 17, and 32 women.

\section{Instruments and Procedure}

To determine the participants' perceptual language learning style preferences, Chen's (1999) the Chinese version of Learning Channel Preference Checklist (LCPC), revised from O'Brien's (1990) LCPC, was employed. According to Chen (1999), the LCPC is sensitive to variations in style caused by cultural differences and provides a useful inventory with high reliability (Oxford, 1992; Kroonenberg, 1995; Oxford, 1995, as cited in Chen, 1999). The LCPC, which includes 36 statements, is a selfscoring inventory with three perceptual categories of learning style preference: visual, auditory, and haptic (kinesthetic and tactile). On a 5-point Likert scale ranging from 1 (almost never) to 5 (almost always), the LCPC measures how often the respondent uses each style. Chen's LCPC has a test-retest reliability of .86 with face validity confirmed by five EFL teaching experts. 
Here, all participants filled out the LCPC questionnaire, and then, we analyzed the participants' backgrounds.

\section{Data Analysis}

Data were first analyzed based on the total scores in all three categories: the sum of items $1,5,9,10,11,16,17,22,26,27,32$, and 36 indicated the visual preference score; the sum of items $2,3,12,13,15,19,20,23,24,28,29$, and 33 indicated the auditory preference score; and the sum of the remaining items indicated the haptic preference score. Style preference scores were transformed into percentages, with the highest percentage indicating a participant's major learning style. First, a descriptive quantitative survey was used to determine different college majors' learning style preferences. Because the chi-square test was used to test whether two variables are related or are independent of each other, followed by analysis of the relationships between categorical variables (i.e., whether students with different majors [business, IT, design] consistently gravitated towards their learning style preferences [visual, auditory, and haptic]).

\section{Results and Discussion}

\section{Learning Styles and Majors}

Table 1 lists the mean scores of learning style preferences among students with different majors. Business majors preferred visual style $(M=41.63, S D=5.11)$, followed by auditory $(M$ $=38.08, S D=6.10)$ and haptic $(M=37.90, S D$ $=6.61$ ) styles. IT majors also used visual style more $(M=39.15, S D=5.75)$, followed by haptic $(M=38.65, S D=5.28)$ and auditory $(M=36.68$,
$S D=5.08)$ styles. Design majors preferred the visual style $(M=41.48, S D=5.34)$, followed by haptic $(M=38.75, S D=5.84)$ and auditory $(M=$ $38.48, S D=5.00$ ) styles. In summary, all groups preferred visual style. Business and IT majors' second preference was the auditory style followed by the haptic style. This finding corroborates that of Sarabi-Asiabar et al. (2015) and Alkooheji and Al-Hattami (2018): among learning styles, students with different majors prefer the visual learning style. Students across certain majors appear to have the identical preferences when they process and retain new information.

In many studies, the visual style has the most commonly been observed as one of the three basic learning styles in the widely used Fleming VARK model: $60 \%-65 \%$ of the general population absorb and recall information the most efficiently visually (Sreendihi \& Helena, 2017). The preference for visual style confirmed in the present study is also corroborated by Lee's 1976 finding: "Asian cultures emphasized the visual mode for learning their largely iconographic language systems" (as cited in Sun, 2011 , p. 350). This learning style preference may be influenced by the teaching context throughout students' language learning. The participants in the current and previous studies appear to learn well by using the visual learning style (i.e., from seeing words in books, on the chalkboard, and in workbooks).

\section{Relationship Between Learning Styles and Majors}

Table 2 presents the distribution of LCPC 
learning styles across business, IT, and design majors. In the visual (V) domain, 24 respondents were business majors, 18 were IT majors, and 19 were design majors. In the auditory (A) domain, 4 respondents were business majors, 10 were IT majors, and 7 were design majors. In the haptic $(\mathrm{H})$ domain, only one respondent was an IT major. In the V\&A domain, two respondents were from IT, while only one was from design. In the V\&H domain, one respondent was a business major, one an IT major, and one a design major. In the final (V\&A\&H) domain, two respondents were business majors, three were IT major, and one was a design major. These findings indicate that students of the three majors preferred to use a single learning style, whether 61 students preferred the visual style
(50.8\%), 30 haptic $(25 \%)$, or 16 auditory (13.3\%). Only a few students used a bi- or tri-modal of the styles: two IT majors and one design major used V\&A; one business major, one IT major, and one design major used $\mathrm{V} \& \mathrm{H}$; and a mixture of visual, auditory, and haptic styles was used by three respondents from IT, two from business, and one from design. The marked observation of such single style preferences, as opposed to bi- or trimodal style usage, contradicts the findings of Sarabi-Asiabar et al. (2015), which indicated that 89 Iranian students $(48.4 \%)$ preferred a singlemodal learning style, whereas the remaining 95 $(51.6 \%)$ preferred multimodal learning style. This may be explained by the different cultural environment, which affects the way students receive and process information.

Table 1 Descriptive Statistics of Learning Style Preferences for Different Majors

\begin{tabular}{llllllll}
\hline Level & \multicolumn{3}{c}{ Business (N=40) } & Information (N=40) & \multicolumn{2}{c}{ Design (N=40) } \\
Style preference & Mean & SD & Mean & SD & Mean & SD \\
\hline Visual & 41.63 & 5.11 & 39.15 & 5.75 & 41.48 & 5.34 \\
Auditory & 38.08 & 6.10 & 36.68 & 5.08 & 38.48 & 5.00 \\
Haptic & 37.90 & 6.61 & 38.65 & 5.28 & 38.75 & 5.84 \\
\hline
\end{tabular}

Table 2 Distribution of Learning Styles and Majors

\begin{tabular}{llllllllll}
\hline \multirow{2}{*}{ Majors } & \multicolumn{8}{c}{ Styles } & \multicolumn{2}{c}{ Total } \\
& & V & A & H & A\&H & V\&A & V\&H & V, A \&H & \\
\hline Business & 24 & 4 & 9 & 0 & 0 & 1 & 2 & 40 \\
Information & 18 & 5 & 10 & 1 & 2 & 1 & 3 & 40 \\
Design & 19 & 7 & 11 & 0 & 1 & 1 & 1 & 40 \\
Total & 61 & 16 & 30 & 1 & 3 & 3 & 6 & 120 \\
\hline
\end{tabular}


Table 3 presents the alignment of learning styles with students' majors. No significant difference was found $(p=.439)$, corroborating the findings of Sarabi-Asiabar et al. (2015). The implications of these findings may be of help to teachers as they strive to provide an optimal classroom learning environment (Felder, 1995).

Table 3 Pearson Chi-Square Test Results for Learning Styles and Majors

\begin{tabular}{llccc}
\hline & \multicolumn{2}{c}{ Chi-square Test } & \\
& Value & df & Sig. \\
\hline Pearson Chi-square & $12.086^{\mathrm{a}}$ & 12 & .439 \\
Likelihood Ratio & 13.243 & 12 & .352 \\
N of valid cases & 120 & & \\
\hline
\end{tabular}

Note. ${ }^{*} p<.05$

As the results demonstrate, students with different majors preferred various styles; however, the relationship between styles and majors appears to be non-significant. These findings corroborate those reported previously: learning styles may be context dependent, and styles vary across cultures, countries, and nationalities (Reid, 1987; Rossi-Le, 1995; Tyacke, 1998, as cited in Naserieh \& Sarab, 2013).

\section{Conclusions}

Here, among all learning styles, our students preferred the visual learning style the most across all the selected majors, but these results were non-significant. As Bicer (2014) assumed, every individual is different, so any single variable like learning style, gender, or learning background may not aid in determining how an individual's learning style can support the complexity of the human brain. Thus, Gohar and Sadeghi (2015) asserted, "the variable of learning style is just one of the many factors which impact the learning process and outcomes" (p. 762). Additional studies investigating the influence of educational backgrounds on EFL students' learning styles are warranted.

Because learning styles remain an unpredictable variable in the learning process, effective course design should recognize the prevailing learning styles. However, to effectively engage all students, a teacher must create different opportunities to engage in the learning process, thereby increasing overall course satisfaction (Powers, 2016).

Although the existing classroom activities may reflect students' learning style preferences, teachers are encouraged to think about how they engage their students in the learning process. For instance, to more effectively support visual learners, class lectures can be enriched with video or replaced with visual AJERR: https://escipub.com/american-journal-of-educational-research-and-reviews/ 
effects and presentations in classes. However, only by exposing learners to different learning styles can teachers demonstrate the benefits of different learning styles across various courses and majors.

\section{References}

[1] Alkooheji, L., \& Al-Hattami, A. (2018). Learning Style Preferences among College Students. International Education Studies, 11, 50-63.

https://doi.org/10.5539/ies.v11n10p50

[2] Awang, H., Samad, N. A., Mohd Faiz, N. Z., Roddin, R., \& Kankia, J. D. (2017). Relationship between Learning Styles Preferences and Academic Achievement. International Research and Innovation Summit, 226, 1-5

[3] Bailey, P. Onwuegbuzie, A. J., \& Daley, C. E. (2000). Using Learning Style to Predict Foreign Language Achievement at the College Level. System, 28, 115-133.

[4] Bicer, D. (2014). The Effect of Students' and Instructors' Learning Styles on Achievement of Foreign Language Preparatory School Students. Procedia-Social and Behavioral Sciences, 141, 382-386.

https://doi.org/10.1016/j.sbspro.2014.05.067

[5] Chen, Y. C. (1999). The perceptual learning style preferences of Taiwanese junior high school students in learning English. Unpublished master thesis, National Changhua University of Education, Changhua, Taiwan.

[6] Chen, C., Jones, K. T. \& Xu, A. S. (2018). The Association between Students' Style of Learning Preferences, Social Presence, Collaborative Learning and Learning Outcomes. Journal of Educators Online, 15(1). 1-16
[7] Cimermanova, I. (2018). The effect of learning styles on academic achievement in different forms of teaching. International Journal of Instruction, 11(3), 219-232.

[8] Cutolo, A., \& Rochford, R. A. (2007). An Analysis of Freshmen Learning Styles and Their Relationship to Academic Achievement. College Quarterly, 10, 1-17.

[9] Dai, Y., Wu, Z. \& Dai, L. (2015). The Relationships among Motivation, Learning Styles and English Proficiency in EFL Music Students. International Journal of English Linguistics, 5(6), 75-83

[10] Dunn, R., Dunn, K., Price, G. E. (1991). Productivity Environmental Preference Survey. Price Systems, Inc., Lawrence, KS.

[11] Fleming, N. D. (1995). I'm different; not dumb. Modes of presentation (VARK) in the tertiary classroom. In Zelmer, A., (ed.) Research and Development in Higher Education. Proceedings of the 1995 Annual Conference of the Higher Education and Research Development Society of Australia (HERDSA), pp. 308-313.

[12] Fleming, N.D. and Mills, C. (1992) Not Another Inventory, Rather a Catalyst for Reflection. To Improve the Academy, 11, 137.

[13] Felder, R. M. \& Silverman, L. K. (1988). Learning and teaching styles in engineering education. Engineering Education, 78(7), 674-781.

[14] Felder, R. M., \& Soloman, B. A. (1996). Index of Learning Styles. Retrieved from http://www.engr.ncsu.edu/learningstyes/ilsweb. html

[15] Gohar, M. J., \& Sadeghi, N. (2015). The Impact of Learning Style of Preferences on Foreign AJERR: https://escipub.com/american-journal-of-educational-research-and-reviews/ 
Language Achievement: A Case Study of Iranian

EFL Students. Procedia-Social and Behavioral

Sciences, $171,754-764$.

https://doi.org/10.1016/j.sbspro.2015.01.188

[16] Jiraporncharoen, W., Angkurawaranon C., Chockjamsai, M., Deesomchok, A. \& Euathrongchit, J. (2015). Learning styles and academic achievement among undergraduate medical students in Thailand, J Educ Eval Health Prof, 12- 38.

http://dx.doi.org/10.3352/jeehp.2015.12.38

[17] Kolb, D. A. (1984). Experiential Learning: Experience as the source of learning and development. Englewood Cliff, NJ: Prentice-Hall.

[18] Liu, F., Hu, L., \& Gan, J.J. (2013). A study on the Learning Style Preferences with Different Academic Backgrounds-Taking Tujia EFL Learners As examples. Theory and Practice in Language Studies, 3, 100-107.

[19] https://doi.org/10.4304/tpls.3.1.100-

107.Naserieh, F., \& Sarab, M. R. A. (2013). Perceptual Learning Style Preferences among Iranian Graduate Students. System, 41, 122-133. https://doi.org/10.1016/j.system.2013.01.018

[20] O'Brien, L., (1990). Learning Channel Preference Checklist (LCPC). Specific Diagnostic Services, Rockville, MD.

[21] Power, C. M. (2016). Music Student Satisfaction: The Relationship Between Learning Style Preferences and Major Satisfaction, Unpublished Master Thesis, Knoxville: The University of Tennessee

[22] Reid, J. M. (1984). Perceptual Learning Style Preference Questionnaire. University of
Wyoming, Department of English, Laramie.

[23] Riechmann, S. W. \& Grasha, A. F. (1974). A rational approach to developing and assessing the construct validity of a student learning style scales instrument. The journal of Psychology, 97, 213-223.

[24] Sreendihi, S. K. \& Helena, T. C. (2017). Styles of learning based on the research of Fernald, Keller, Orton, Gillingham, Stillman, Montessori, and Neil D. Fleming. International Journal for Innovative Research in Multidisciplinary Field, 3(4), 17-25.

[25] Sarabi-Asiabar, A., Jafari, M, Sadeghifar, J., Tofighi, S, Rouhollah, Z., Peyman, H, \& Shams, J. (2015). The relationship between learning style preferences and gender, educational major and status in first year medical students: A survey study from Iran. Iran Red Crescent Med Journal, 17(1). Available from: https://www.semanticscholar.org/paper/TheRelationship-Between-Learning-StylePreferences-Sarabi-AsiabarJafari/f2a914d96db8c4db444da57ed4eb46562 $8 c 51094$

[26] Soureshjani, K. H. \& Naseri, N. (2012). Perceptual Learning-Style Preferences of Iranian EFL Learners in Relation to Their Proficiency Level. American Journal of $\begin{array}{llll}\text { Linguistics, } & 1(4), \quad 70-74 \quad \text { DOI: }\end{array}$ 10.5923/j.linguistics.20120104.01

[27] Sun, M. L. (2011). Experimental study of Chinese non-English students' overall learning style preferences. US-China Education Review A3, p. 346-354

[28] Tuckman, B. W, (1999). Conducting Educational 
I-Ju Chen et al., AJERR, 2021; 6:81

Research, $5^{\text {th }}$ ed. Orlando, FL: Harcourt Brace.

[29] Uhrig, K. (2015). Learning styles and strategies for language use in the context of academic reading tasks. System, 50, 21-31.

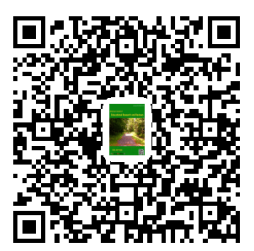

